This item was submitted to Loughborough's Research Repository by the author.

Items in Figshare are protected by copyright, with all rights reserved, unless otherwise indicated.

\title{
Analysis of friction-induced vibration leading to brake squeal using a three degree-of-freedom model
}

PLEASE CITE THE PUBLISHED VERSION

http://dx.doi.org/10.1007/s11249-017-0887-8

\section{PUBLISHER}

(C) Springer

VERSION

AM (Accepted Manuscript)

\section{PUBLISHER STATEMENT}

This work is made available according to the conditions of the Creative Commons Attribution-NonCommercialNoDerivatives 4.0 International (CC BY-NC-ND 4.0) licence. Full details of this licence are available at: https://creativecommons.org/licenses/by-nc-nd/4.0/

\section{LICENCE}

CC BY-NC-ND 4.0

\section{REPOSITORY RECORD}

Lyu, Hongming, Stephen J. Walsh, Guangxiong Chen, Lijun Zhang, Kuncai Qian, and Lei Wang. 2017. "Analysis of Friction-induced Vibration Leading to Brake Squeal Using a Three Degree-of-freedom Model". figshare. https://hdl.handle.net/2134/25931. 


\title{
Analysis of Friction-Induced Vibration Leading to Brake Squeal Using a Three Degree-of- Freedom Model
}

\author{
Hongming Lyu ${ }^{1,5}$, Stephen James Walsh ${ }^{2}$, Guangxiong Chen ${ }^{1}$, Lijun Zhang ${ }^{3}$, Kuncai Qian ${ }^{4}$, Lei Wang ${ }^{4}$
}

1 School of Mechanical Engineering, Southwest Jiaotong University, Chengdu 610031, China

2 Department of Aeronautical and Automotive Engineering, Loughborough University, Loughborough, LE11 3TU, UK

3 College of Automotive Studies, Tongji University, Shanghai 201804, China

4 Technology Center, CRRC Qishuyan Institute Co., Ltd., Changzhou 213011, China

5 School of Automotive Engineering, Yancheng Institute of Technology, Yancheng 224051, China

\section{Abstract}

Friction-induced vibration is a common phenomenon in nature and thus has attracted many researchers' attention. Many of the mathematical models that have been proposed on the basis of mode coupling principle, however, cannot be utilized directly to analyse the generation of friction-induced vibration that occurs between two bodies because of a difficulty relating model parameters to definite physical meaning for real friction pairs. In this paper, a brake squeal experiment is firstly carried out by using a simple beam-on-disc laboratory apparatus. Experimental results show that brake squeal correlates with the bending mode of the beam and the nodal diameter out-of-plane mode of the disc as well as the cantilever length of the beam. Then, a specific three degree-of-freedom dynamic model is developed of the beamon-disc system and the vibration behaviour is simulated by using the complex eigenvalue analysis method and a transient response analysis. Numerical simulation shows that the bending mode frequency of the beam a little greater than the frequency of the nodal diameter out-of-plane mode and a specific incline angle of the leading area to the normal line of the disc as well as a certain friction coefficient, are necessary conditions for the mode coupling of a frictional system. Results also show that when the frictional system is transited from a steady state to an unstable state for the variation of parameters, its kinetic and potential energy increase with time due to continuous feed-in energy from the friction force while the dynamic responses of the system change from the beating oscillation to the divergent, which leads to the friction-induced vibration and squeal noise.

\section{Keywords}

Friction-induced vibration; Brake squeal; Instability; Three degree-of-freedom model; Mode coupling

Cite this article as: Lyn, H., Walsh, S.J., Chen, G. et al. Tribol Lett (2017) 65: 105. doi:10.1007/s11249-017-0887-8 


\section{Introduction}

Friction-induced vibration due to sliding contact between two objects is a common phenomenon in nature. Examples of this are a violin sound, a cricket chirp, wheel/rail noise, brake squeal, machining chatter, earthquake motion, etc. Utilizing or preventing frictioninduced vibration in different occasions is of great significance for society and industry [1]. Much research has been conducted on this issue, especially the brake squeal from the aspects of generation mechanism, influence factors, numerical simulation, experimental analysis and elimination countermeasures. Among these, the generation mechanism is still a concern of research because of its fundamental role [23].

Bowden thought that the variation in the friction coefficient with sliding velocity was the cause of stick-slip vibration [4]. Not only the difference between the static and kinetic coefficient of friction but also the negative slope of the friction-velocity curve could lead to a stick-slip behaviour and produce self-excited vibration $[5,6]$.

Spurr proposed a sprag-slip model to explain the generation mechanism of brake squeal [7]. As a rigid articulated bar in friction contact with a rigid moving surface at an inclined angle that equals the friction angle, the bar could be spragged or self-locked and then followed by a slip due to a displacement of its flexibly supported end. This is known as geometrically induced or kinematic constraint instability, which occurs even though the coefficient of friction is constant [8].

Tlusty firstly presented a mode coupling principle to study the formation of machining chatter by using a two degree-of-freedom (DOF) dynamic model [9]. North built an 8-DOF lumped-parameter model for disc brake squeal considering the translation and rotation motions of the disc, pads and calliper. He proposed a "binary flutter mechanism" by using a simplified 2-DOF model referred from an airfoil flutter theory. The dynamical system of a brake may be unstable if two modes of the disc under the action of friction. The theoretical solution can be obtained by deducing the eigenvalues of dynamical equations [10-12]. Earles built a 2-DOF model and a 4-DOF model with two masses based on a beam-on-disc system to investigate the problem of brake squeal $[13,14]$ while Hamabe built a single-mass and 2DOF model [15]. But no contact stiffness between contact surfaces was considered in these models. Hoffmann proposed a concise 2-DOF mass-spring-belt model by introducing the contact stiffness between the mass and the belt. In this model, both normal force and the frictional force are assumed to be functions of the contact stiffness and the normal displacement of the mass. Therefore, the non-conservative frictional force leads to an asymmetric stiffness matrix and an eigenvalue solution of the resulting problem may be utilized to analyse the frictional instability. This model not only illustrated the role of contact stiffness but also provided a clear explanation of the mode coupling principle of frictioninduced vibration $[16,17]$, and therefore has been referred widely in the works of other scholars. In addition, Millner built a 6-DOF lumped-parameter model including the translation and rotation motions of the disc, pad and calliper [18]. Ahamed proposed a 10 DOF model for a fixed calliper disc brake considering both translation and rotation motions of the disc, pads and pistons [19]. Papinniemi extended a 4-DOF model from Hoffman's 2DOF model plus the disc motions in normal and tangential directions [20]. Oura proposed a 3 -DOF model for a pad-on-disc system including the rotation and translation motions of the pad as well as the translation motion of the disc [21, 22]. These models mentioned above 
revealed that even when the friction coefficient is constant, the systems may be unstable if the friction force couples related degrees-of-freedom together [23]. However, it is difficult to attribute definite physical meaning to the parameters of these models and thus they cannot be applied directly to analyse the instability problem of real friction pairs.

Hoffmann and his colleagues also performed a lot of work on the experiment and modelling of a beam-on-disc system. Tuchinda built a continuum mathematical model of a disc and a beam to simulate the mode lock-in behaviour. Although in this model the beam axis is inclined along the disc rotation, numerical simulation showed that the friction system would be unstable only when the incline angle of the axis is taken as a negative value, i.e., the beam inclination is opposite to the disc rotation [24]. To solve this contradiction, Tuchinda thought the contact point should be the corner of the contact surface of the beam. However, finite element analysis showed that there exists a small discrepancy between theoretical predictions and measurements when the beam is inclined at $4^{\circ}[25]$. Based on a specially designed beamon-disc test apparatus, Allgaier found that when the cantilever length of an aluminium beam equals $156.7 \mathrm{~mm}$ and the incline angle of the beam axis against the aluminium disc is $4^{\circ}$, the third nodal diameter out-of-plane mode will be coupled with the second bending mode of the beam, which leads to friction-induced squeal. A finite element model was built to analyse the effects of the rotation speed of the disc and the applied normal load on friction-induced vibration [26].

Akay et al. carried out a lot on experiments and finite element simulations based on different beam-on-disc test rigs [27-30], and summarized the research results in Ref. [31]. Because of the contact effect of a brake pad, the nodal diameter out-of-plane mode will split into two modes which have the same mode shapes but different phases and frequencies [2729]. When the frequency of a split mode at higher frequency is close to the bending mode frequency of the pad, both modes will be coupled. By adjusting the beam length, added mass, different system modes may be coupled to generate squeal noise at different frequencies. Experimental results showed that when the beam length equals $180 \mathrm{~mm}$, several disc modes are coupled with several beam modes simultaneously, i.e., a squeal noise occurs at a mixed frequency [30, 31].

With the development of computation technology, the mode coupling-based finite element (FE) method has established itself as the most common numerical method used for predicting the instability of real friction pairs [32-34]. However, much research showed that brake squeal is actually influenced by many factors such as component geometry, material property, friction coefficient, contact interface, applied load and thermal effect. Because most of the influence factors are time-varying and difficult to model accurately, application of FE method is still far from satisfactory and results often suffer from over-prediction or underprediction $[35,36]$.

Therefore, the generation mechanism and reduction countermeasures of friction-induced squeal for real brakes still need further investigation. Experiment research based on beamon-disc or pin-on-disc systems is an effective way to investigate the essential of frictioninduced squeal. Because a single-mass model cannot incorporate the main motions of a real frictional pair while those models with many degree-of-freedoms are actually difficult to obtain the corresponding parameters, the lumped-parameter models mentioned above may be used to explain the mode coupling principle but is still not suitable for investigating the problem of friction-induced vibration occurs between two bodies. In addition, the rotation 
degree-of-freedom of a frictional part such as a pad, a beam or a pin that also proposed in some models may not represent the real motion.

In order to clearly illustrate the generation of friction-induced vibration due to sliding contact between two objects, a 3-DOF dynamic model incorporating the main motions of a frictional pair and the contact stiffness between frictional interfaces is proposed and analysed in this paper. In Sect. 2, a simple beam-on-disc brake squeal experimental apparatus is introduced. The relationship between the brake squeal frequency and the mode frequencies of the beam and disc as well as the cantilever length of the beam is extracted from experiment results. In Sect. 3, a specific 3-DOF lumped-parameter model of friction-induced vibration is therefore developed of the beam-on-disc system. In Sect. 4, with the identified and estimated parameters of the experimental apparatus, the instability of a frictional system as well as the influence factors is simulated by using the complex eigenvalue analysis method and a transient response analysis. The relationship among mode coupling, system instability, oscillating behaviour, energy feed-in and brake squeal is analysed and discussed. Finally, some concluding remarks are presented in Sect. 5.

\section{Brake Squeal Experiments of a Beam-on-Disc System}

\subsection{Beam-on-Disc Experimental Apparatus}

For the reason of complication of real brake system on vehicles, it is still difficult to deal with the problem of disc brake squeal. Thus, a beam-on-disc brake squeal apparatus having a simple structure is designed for the experiments in this study. An automobile brake disc (Cast iron) is installed on the lathe machine together with a metal beam (aluminium alloy, $\varphi 28 \mathrm{~mm}$ ). The schematic layout of the experimental apparatus is shown in Fig. 1a. The disc is driven by a motor and through a transmission. The contact end of the beam to the disc is pasted by a piece of friction material while the other end is held by the cutter carrier. The cantilever length of the beam is denoted by the symbol $L$. By using the carriage handle, the axial force $P$ is thus applied on the beam to make it move into contact with the surface of the rotating disc and produce brake squeal. The sound pressure of brake squeal is measured by a microphone and output to a data acquisition system for further analysis. A photograph of the beam-on-disc brake squeal apparatus is shown in Fig. 1 b.

(a)

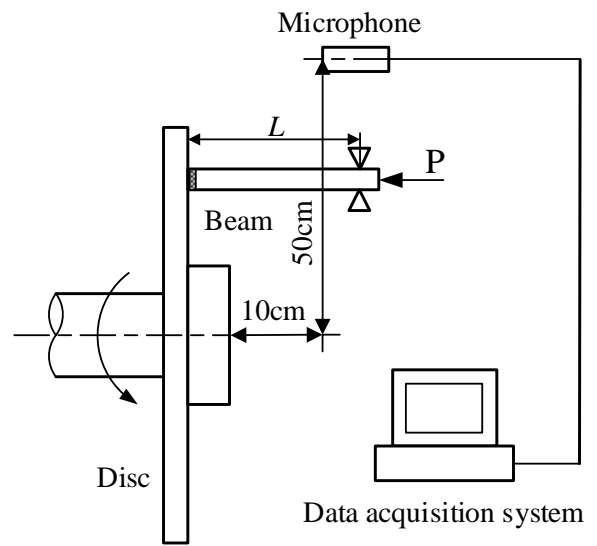

(b)

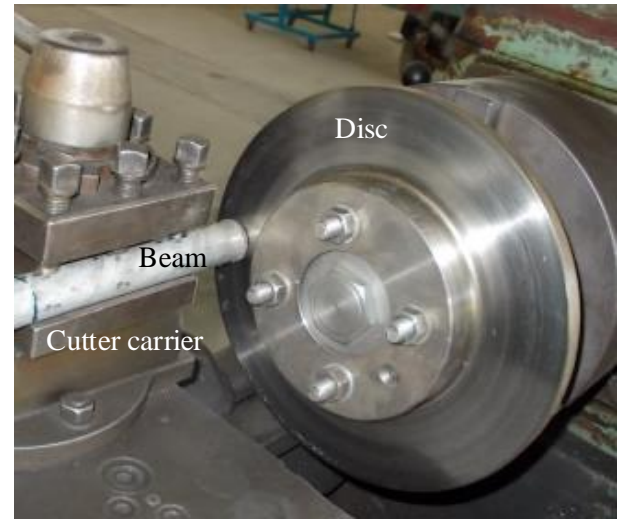

Fig. 1. Beam-on-disc brake squeal apparatus: (a) schematic layout and (b) photograph. 


\subsection{Brake Squeal Experimental Method and Results}

Firstly, the cantilever length of the aluminium alloy beam is adjusted to $90 \mathrm{~mm}$ by changing its installation position, and then the disc is rotated at a speed of about $18 \mathrm{rpm}$. Brake squeal due to friction-induced vibration is triggered intermittently. The sound of disc brake squeal produced during the whole process from start to finish is measured and analysed as shown in Fig. 2. Because of the influence of disc surface run-out (SRO), the sound signal is repeated in each disc rotation. It can be seen that similar brake squeal generated in the range between 2.9 and $6.2 \mathrm{~s}$ is repeated again between 6.2 and $9.5 \mathrm{~s}$. The FFT analysis shows that the frequencies of brake squeal noise are $1637 \mathrm{~Hz}$ and its harmonics. The dominant frequency is near the second frequency of the nodal diameter out-of-plane mode of the constrained disc $(1529 \mathrm{~Hz})$ and the first frequency of the bending mode of the constrained beam $(1563 \mathrm{~Hz})$. Both mode frequencies of the disc and the beam are extracted from experimental hammer impact tests.

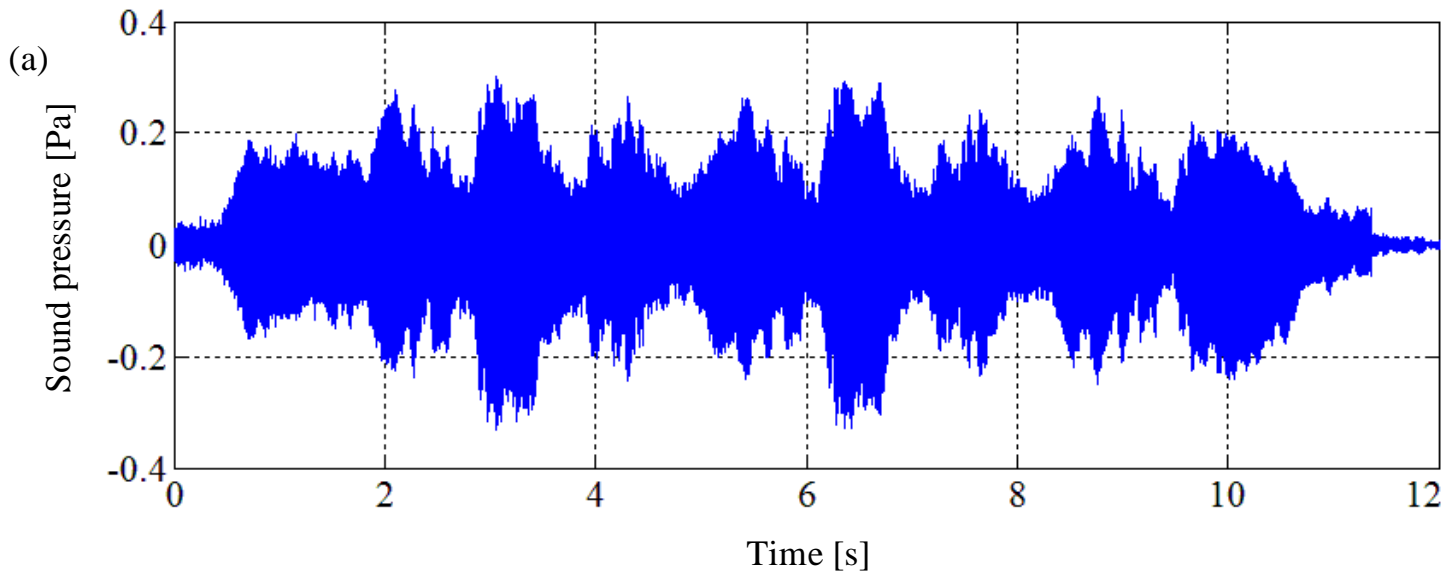

(b)

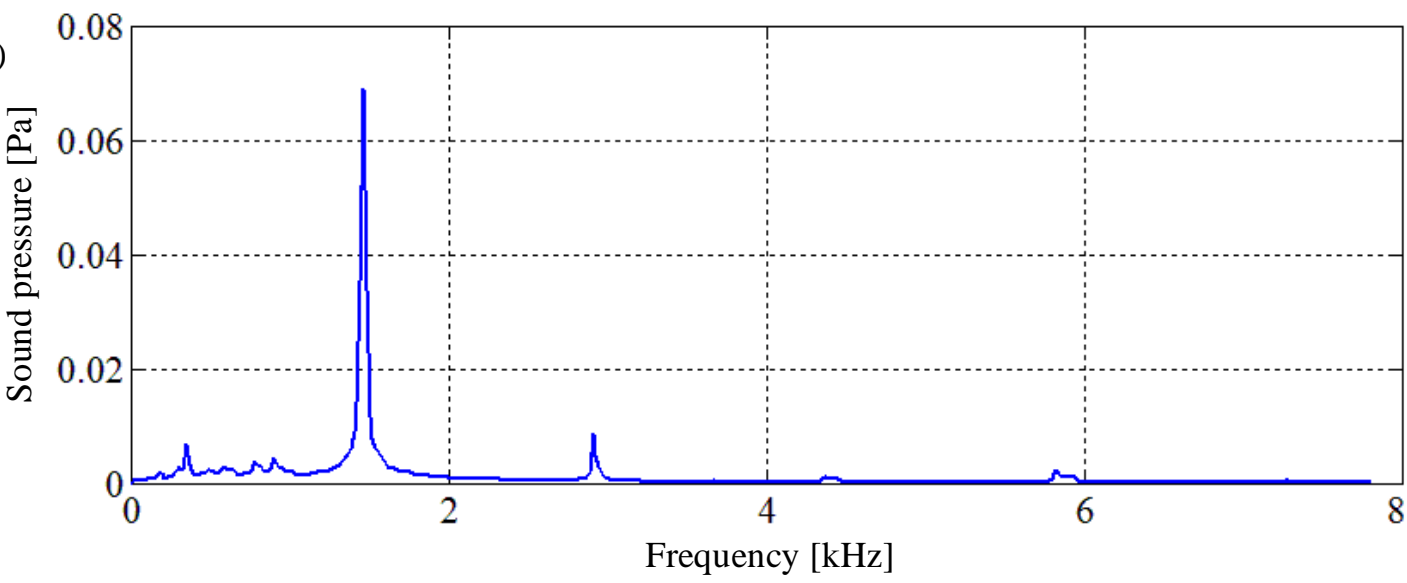

Fig. 2. Signal characteristics of beam-on-disc brake squeal: (a) time history and (b) frequency spectrum.

Similar brake squeal experiments are repeated except that the cantilever length $L$ of the beam is adjusted gradually. When the cantilever beam is adjusted at the length from 50 to $300 \mathrm{~mm}$, it is found that the dominant frequency of brake squeal changes with the cantilever length, as shown in Fig. 3. However, when the cantilever length is less than $50 \mathrm{~mm}$, greater than $290 \mathrm{~mm}$, or in the range from 110 to $155 \mathrm{~mm}$, no squeal noise is observed in the 
experiment. In Fig. 3, the cantilever length of the beam is shown along the $x$-axis while the frequency of brake squeal is shown along the $y$-axis. Results show that the frequency of brake squeal decreases as the cantilever length increases from 50 to $110 \mathrm{~mm}$. The brake squeal appears again at $L=155 \mathrm{~mm}$ and then decreases in frequency from 3704 to $1306 \mathrm{~Hz}$ as the cantilever length increases from 155 to $290 \mathrm{~mm}$. Unlike the squeal noise of a real disc brake occurs indefinitely because of many uncertain influence factors, the friction-induced squeal of the beam-on-disc system at different frequencies always appears and therefore can be repeated when the cantilever beam is adjusted to the same length.

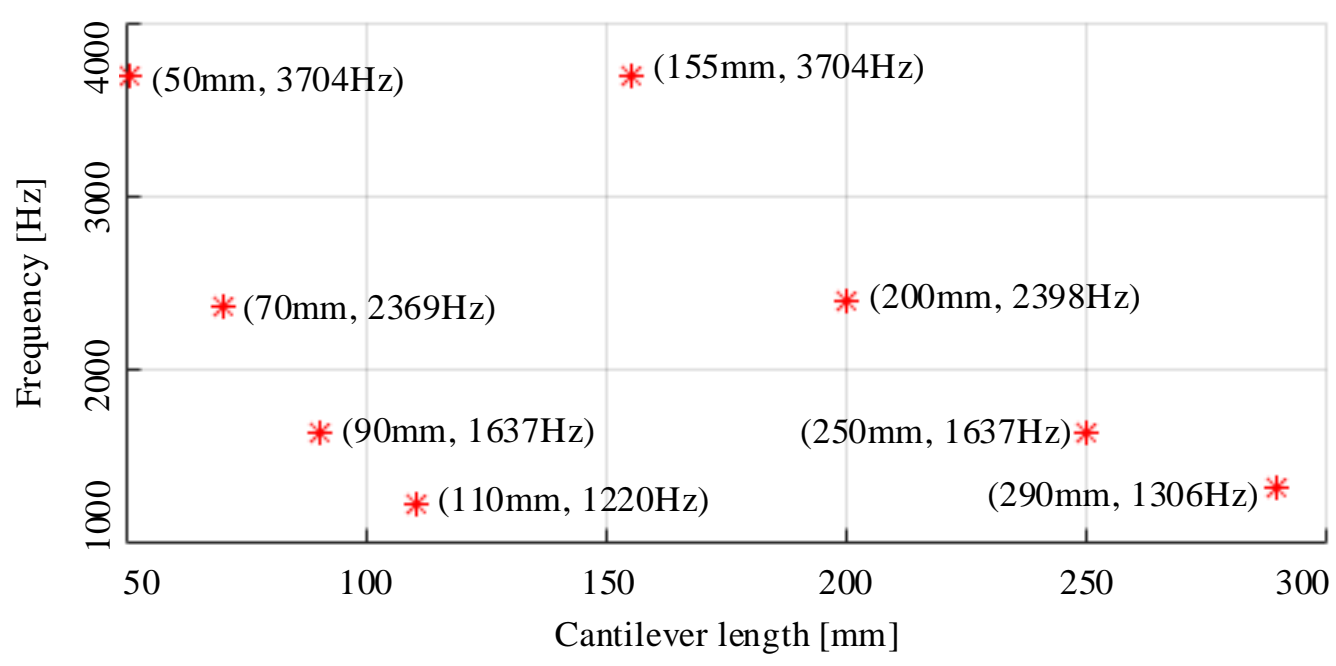

Fig. 3. Brake squeal frequency vs. cantilever length ( $L=50 \mathrm{~mm}$ to $300 \mathrm{~mm})$.

Considered the brake squeal frequency relates well with the geometric structure of the system, the relationships between the squeal frequency, the first four nodal diameter out-ofplane modes of the constrained disc and the first two bending modes of the constrained beam are illustrated in Fig. 4a, b, respectively. Figure 4a shows that the first bending mode frequency of the beam plays an important role in triggering brake squeal. When the cantilever length is equal to $50,70,90$ or $110 \mathrm{~mm}$, the first bending mode frequency of the beam is close to the fourth, third, second or first frequency of the nodal diameter out-of-plane modes of the disc, respectively. Thus, the system generates brake squeal at an adjacent frequency to both the mode frequencies of the disc and the beam. Figure $4 \mathrm{~b}$ shows that the second bending mode frequency of the beam is also important. When the cantilever length equals 155, 200, 250 or $290 \mathrm{~mm}$, the second bending mode frequency of the beam is close to the fourth, third, second or first frequency of the nodal diameter out-of-plane modes of the disc, respectively. Thus, it produces brake squeal at a frequency near to both mode frequencies of the disc and the beam. Because no squeal noise at other frequencies are produced no matter how the cantilever length is adjusted in the range from 110 to $155 \mathrm{~mm}$, it is thought that the first four nodal diameter out-of-plane modes of the constrained disc and the first two bending modes of the constrained beam may be much easier to excite than other modes to produce squeal noise. 

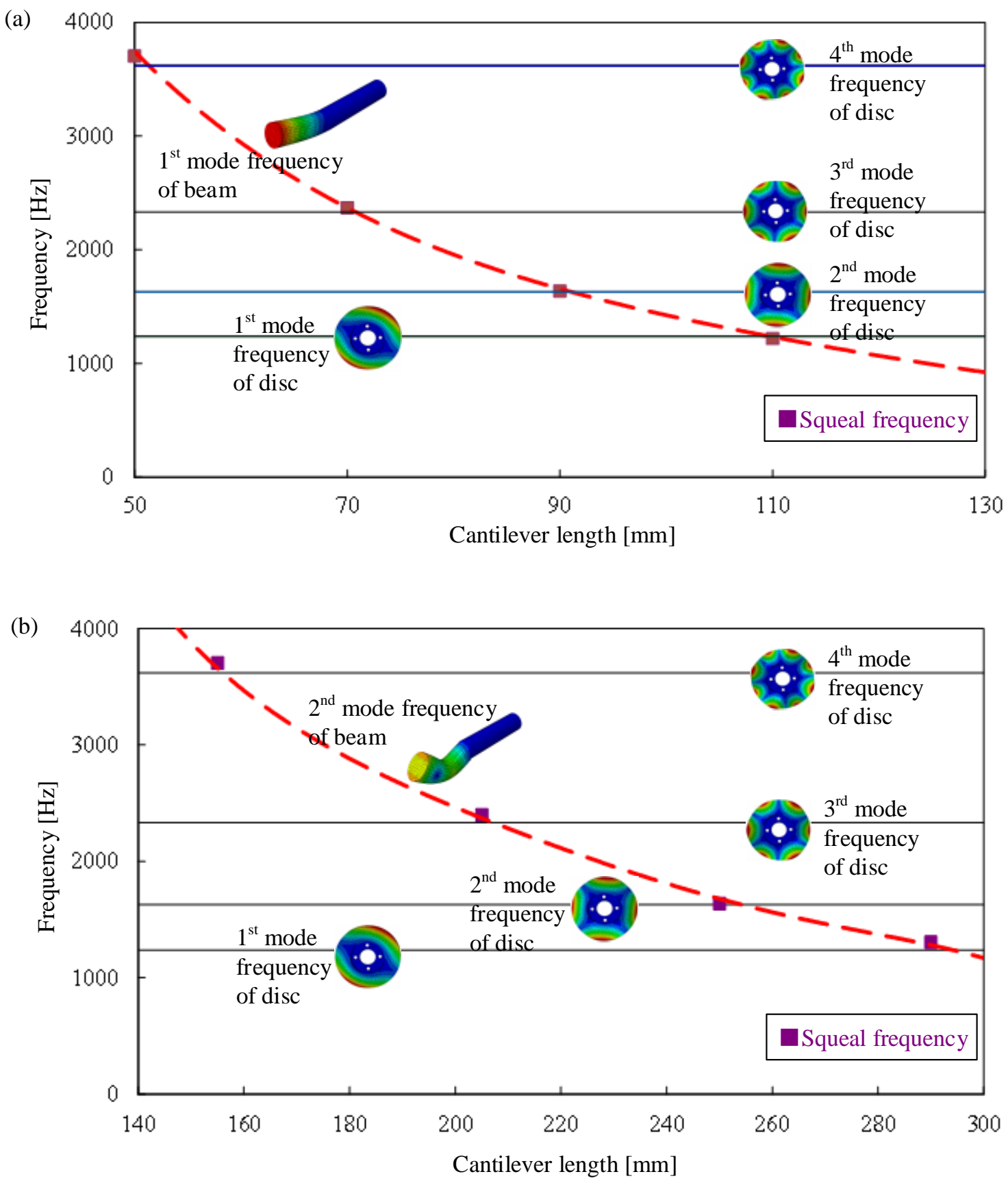

Fig. 4. Relationship between brake squeal frequency ( $\boldsymbol{\square})$, the modes of the beam (dashed line) and the modes of the disc (solid line): (a) $L=50 \mathrm{~mm}$ to $130 \mathrm{~mm}$ and (b) $L=140 \mathrm{~mm}$ to $300 \mathrm{~mm}$.

Therefore, it is concluded from the experiments that the generation of brake squeal of the beam-on-disc system is mostly related to the frequencies of the first four nodal diameter out-of-plane modes of the constrained disc and the first two bending modes of the constrained beam. It seems that when they are close to each other, brake squeal is prone to produce at a coupled mode frequency. If they are separated to a certain degree, the brake squeal may disappear or appear at another coupled mode frequency of the next order. But the generation mechanism of friction-induced squeal as well as its main influence factors still needs a further theoretical analysis. 


\section{A 3-DOF Model of Friction-Induced Vibration}

For a rotating beam-on-disc system, the contact end of the beam usually deflects by a small displacement along the tangential direction of disc rotation due to the action of frictional force, as shown in Fig. 5. The leading area of the contact end of the beam is the actual contact position and creates a digging-in effect while the trailing area is out of touch with the disc surface in the friction process. Therefore, the line from the actual contact point to the installation point is inclined at a small angle to the original centreline of the beam. Considering the horizontal and vertical motions of the beam as well as the vertical motion of the disc, a 3-DOF mass-spring dynamic model is therefore developed of the beam-on-disc system, as shown in Fig. 6. Here, $m_{1}$ is the mass of the stationary part (beam) which is subjected to the actions of the spring $k_{1}$ at an incline angle $\alpha$ to the horizontal direction as well as the spring $k_{2}$ at the same incline angle $\alpha$ to the vertical direction. $m_{2}$ is the mass of the moving part (disc) which is subjected to the action of the spring $k_{3}$ in the vertical direction. There exists a normal contact stiffness $k_{\mathrm{c}}$, a normal force $N$ and a frictional force $F_{\mathrm{f}}$ between $m_{1}$ and $m_{2}$.

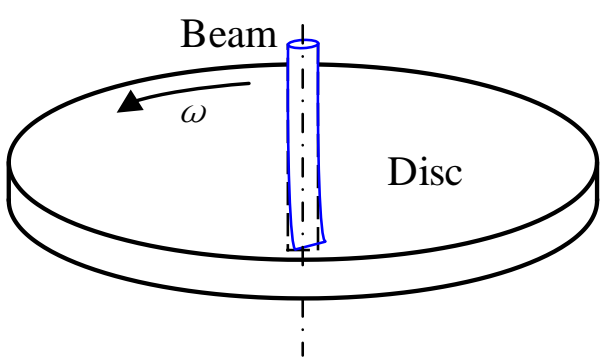

Fig. 5. Schematic diagram of the beam-on-disc system (the solid outline represents the deformed beam and the dashed outline represents the un-deformed beam).

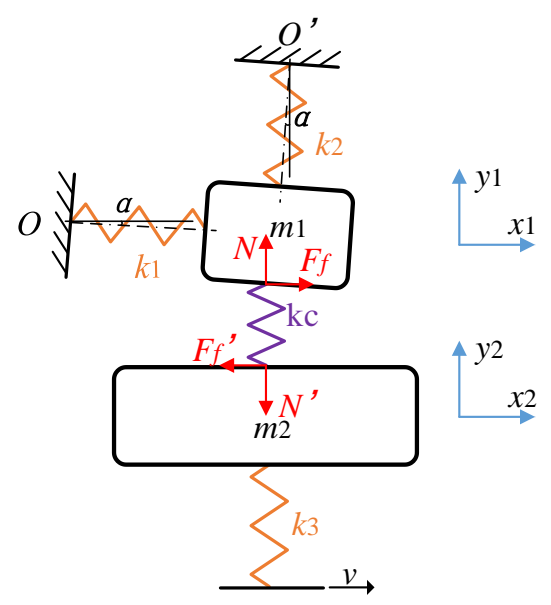

Fig. 6. 3-DOF model of the frictional system.

Assume that: (1) $m_{1}$ is tilted in its perpendicular directions ( $x_{1}$ and $\left.y_{1}\right)$ by an angle $\alpha$ relative to the fixed points ( $O$ and $O^{\prime}$ ) simultaneously; (2) the incline angle $\alpha$ is taken as a constant value to simplify the dynamics analysis process on the basis that the highfrequency and low-amplitude vibration of $m_{1}$ affects the incline angle $\alpha$ only negligibly; (3) $m_{2}$ moves forward continuously at an even speed $v$ along the $x_{2}$ direction and only vibrates in the $y_{2}$ direction; (4) both $m_{1}$ and $m_{2}$ are subjected to the actions of the normal force $N$ and the frictional force $F_{\mathrm{f}}$ during the friction process. The normal force $N$ on the contact spring $k_{\mathrm{c}}$ is proportional to the difference in the vertical displacement $\left(y_{2}-y_{1}\right)$ between $m_{1}$ and $m_{2}$; (5) and that the positive damping of the system is not considered in this model in order to simplify the study. It is obvious that a non-damped frictional system is more convenient to investigate the essence of friction-induced vibration though positive damping exists in actual frictional systems [37, 38].

According to the Newton's Second Law, the equations of motions in the $x_{1}, y_{1}$ and $y_{2}$ directions for the present model are derived as following. 
According to the Newton's Second Law, the equations of motions in the $x_{1}, y_{1}$ and $y_{2}$ directions for the present model are derived as following.

$$
\left\{\begin{array}{l}
m_{1} \ddot{x}_{1}+\left(k_{1} \cos ^{2} \alpha+k_{2} \sin ^{2} \alpha\right) x_{1}+\left(-k_{1}+k_{2}\right) \sin \alpha \cos \alpha y_{1}=F_{f} \\
m_{1} \ddot{y}_{1}+\left(-k_{1}+k_{2}\right) \sin \alpha \cos \alpha x_{1}+\left(k_{1} \sin ^{2} \alpha+k_{2} \cos ^{2} \alpha\right) y_{1}=N \\
m_{2} \ddot{y}_{2}+k_{3} y_{2}=-N
\end{array}\right.
$$

where

$$
N=-k_{c}\left(y_{1}-y_{2}\right)
$$

and

$$
F_{f}=\mu N=-\mu k_{c}\left(y_{1}-y_{2}\right) .
$$

Substituting Eq. (2) and Eq. (3) into Eq. (1), and defining a state vector $\boldsymbol{X}=\left[\begin{array}{lll}x_{1} & y_{1} & y_{2}\end{array}\right]^{\mathrm{T}}$, the system equations can be written in the form of state equation.

$$
M \ddot{X}+\left(K+K_{F}\right) X=0
$$

where

$M=\left[\begin{array}{ccc}m_{1} & 0 & 0 \\ 0 & m_{1} & 0 \\ 0 & 0 & m_{2}\end{array}\right], \quad K=\left[\begin{array}{ccc}k_{1} \cos ^{2} \alpha+k_{2} \sin ^{2} \alpha & -\left(k_{1}-k_{2}\right) \sin \alpha \cos \alpha & 0 \\ -\left(k_{1}-k_{2}\right) \sin \alpha \cos \alpha & k_{1} \sin ^{2} \alpha+k_{2} \cos ^{2} \alpha+k_{c} & -k_{c} \\ 0 & -k_{c} & k_{3}+k_{c}\end{array}\right], \quad K_{F}=\left[\begin{array}{ccc}0 & \mu k_{c} & -\mu k_{c} \\ 0 & 0 & 0 \\ 0 & 0 & 0\end{array}\right]$.

Obviously, the elements in the stiffness matrix $\left(K+K_{F}\right)$ become asymmetrical due to the introduction of the non-conservative frictional force.

\section{Numerical Results and Discussion}

\subsection{Complex Eigenvalue Analysis}

For a time-invariant linear system, the local stability could be analysed through the Routh Hurwitz criterion or the Lyapunov methods. The complex eigenvalue method based on the first Lyapunov method is often utilized to simplify the analysis of frictional instability. According to the complex modal theory, when the dynamic equations contain nonproportional damping, asymmetrical damping or asymmetrical stiffness matrices, the $i$ th eigenvalue $\lambda_{i}$ is can be expressed in the form of a complex number [39]:

$$
\lambda_{i}=\sigma_{i}+j 2 \pi f_{d i}
$$

where the imaginary part $2 \pi f_{\mathrm{d} i}$ is the $i$ th damped natural angular frequency of the system while the real part $\sigma_{i}$ is the respective modal damping factor. The system becomes unstable if one of the real parts reaches a positive value. The $i$ th dimensionless damping factor $\zeta_{i}$ can be expressed in the following form:

$$
\zeta_{i}=-\frac{\sigma_{i}}{2 \pi f_{d i}}
$$

For a dynamic system without positive damping, if the dimensionless damping factor is negative due to the positive real part of the complex eigenvalue, the system is in an unstable state which leads to a divergent oscillation. It is obvious that the greater the absolute value of $\zeta_{i}$, the more unstable is the system. If $\zeta_{i}$ is zero because $\sigma_{i}$ is equal to zero, the system is in 
a stable state. Therefore, both $\sigma_{i}$ and $\zeta_{i}$ are often utilized as the performance index to estimate the instability of frictional systems.

In the present investigation, the masses of the cantilever beam $(L=90 \mathrm{~mm})$ and the disc are calculated or weight, respectively, $m_{1}=0.15 \mathrm{~kg}$ and $m_{2}=4.35 \mathrm{~kg}$. Although the actual beam and disc may have an infinite order of modes and corresponding mode parameters, only the modes related to the brake squeal are considered for the following analysis. The results of an experimental modal test and a finite element analysis show that the first bending mode frequency of the constrained beam $f_{\text {bending }}=1563 \mathrm{~Hz}$, the first tensile mode frequency of the constrained beam $f_{\text {tensile }}=10907 \mathrm{~Hz}$, and the second nodal diameter out-of-plane mode frequency of the constrained $\operatorname{disc} f_{\text {out }}=1529 \mathrm{~Hz}$. Then, the mode stiffness are computed for the proposed 3-DOF dynamic system according to their modal frequencies, thus, $k_{1}=1.45 \times 10^{7} \mathrm{~N} / \mathrm{m}, k_{2}=7.04 \times 10^{8} \mathrm{~N} / \mathrm{m}$ and $k_{3}=4.01 \times 10^{8} \mathrm{~N} / \mathrm{m}$. The contact stiffness between the beam and the disc is estimated according to the material properties and actual contact size of the beam [40], as $k_{\mathrm{c}}=1.50 \times 10^{7} \mathrm{~N} / \mathrm{m}$. When the friction coefficient $\mu$ varies between 0 and 0.8 and the incline angle $\alpha$ varies between $0^{\circ}$ and $16^{\circ}$, the variation of the complex eigenvalue of the 3-DOF frictional system is shown in Fig. 7a, b, respectively.

(a)

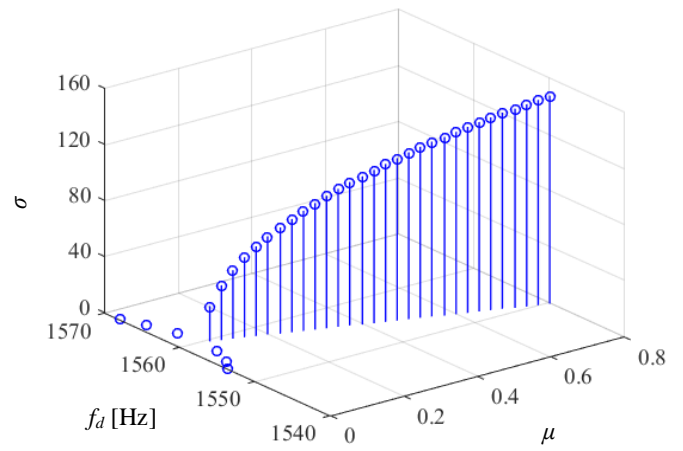

(b)

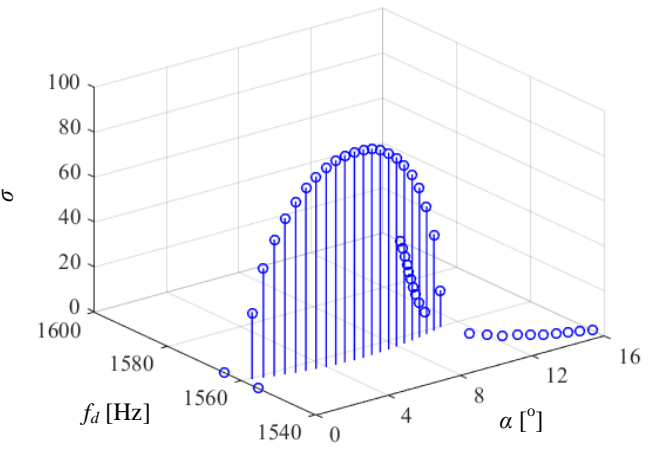

Fig. 7. Influence of the friction coefficient $\mu$ and the incline angle $\alpha$ on the real part $\sigma$ of the complex eigenvalue and the damped natural frequency $f_{d}$ : (a) Influence of the friction coefficient $\mu$ while the incline angle $\alpha=2^{\circ}$ and (b) Influence of the incline angle $\alpha$ while the friction coefficient $\mu=0.2$.

Figure 7a shows that the real part $\sigma$ of the complex eigenvalue is equal to zero and the mode frequencies $f_{\mathrm{d}}$ are separated when the friction coefficient $\mu$ is smaller than 0.05 under the condition of an incline angle $\alpha=2^{\circ}$, which means that the frictional system is in a stable state. However, the real part of the complex eigenvalue becomes positive when the friction coefficient $\mu$ is greater than 0.05 , i.e., both the modes of the disc and the beam are coupled to form an unstable mode, which leads the system to friction-induced vibration.

Figure $7 \mathrm{~b}$ shows that the real part $\sigma$ of the complex eigenvalue is equal to zero and the mode frequencies $f_{\mathrm{d}}$ are separated only when the incline angle $\alpha=0^{\circ}$ or $\alpha>11.5^{\circ}$ under the condition of a friction coefficient $\mu=0.2$, which also means the frictional system is in a stable state. But the real part $\sigma$ of the complex eigenvalue becomes positive when $\alpha$ is in the range from $0^{\circ}$ to $11^{\circ}$, i.e., both the modes of the disc and the beam are coupled to form an unstable mode, which also leads the system to friction-induced vibration.

In order to analyse the combined influence of the friction coefficient $\mu$ and the incline angle $\alpha$ on the system instability simultaneously, the variation of the dimensionless damping 
factor $\zeta$ with $\mu$ and $\alpha$ is shown in Fig. 8. It is found that only when both $\mu$ and $\alpha$ are in a particular range, does the dimensionless damping factor $\zeta$ become smaller than zero, i.e., the frictional system is unstable. The figure also shows that $\zeta$ does not always increase as $\mu$ or $\alpha$ increases.

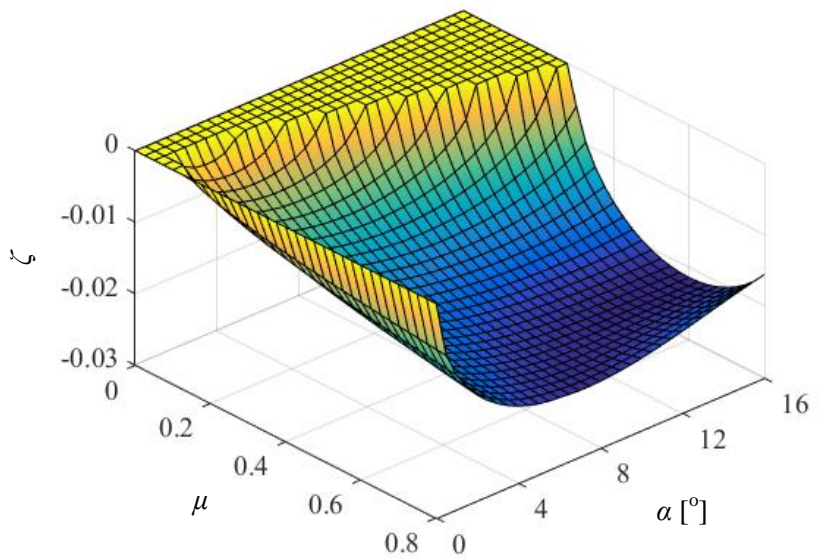

Fig. 8. Influence of the incline angle $\alpha$ and the friction coefficient $\mu$ on the dimensionless damping factor $\zeta$.

There is an interesting phenomenon for such a frictional system with these particular parameters. In the range of $\mu=0-0.25$, the damping factor $\zeta$ is equal to zero when the incline angle $\alpha=0^{\circ}$ or when $\alpha>$ atan $(\mu)$. For example, when $\mu=0.2$ and $\alpha=a \tan (0.2)$, i.e., $\alpha=11.3^{\circ}$, and the system is in a critical stable state. However, it cannot be regarded as a sprag-slip phenomenon. The reason is that the frictional system proposed in this paper is a flexible system while that proposed by Spurr is a rigid system before the articulated bar is locked [7]. In fact, the solution form of a critical unstable condition may be difficult to express in a concise equation for such a 3-DOF dynamic model and is more complicated than that proposed by Spurr.

Because the mode frequencies of a beam change with the cantilever length, frictioninduced squeal is therefore produced at different frequencies. Table 1 lists the comparison of experiment and analysis results. For the reasons of measurement error in experiments and estimation error of contact stiffness for simulation, there exists an error between the experiment and analysis results, but all are smaller than 5\%. This means that the model proposed in this paper has an acceptable level of accuracy and can be applied for further study.

Table 1. Comparison of experiment and analysis results of the squeal frequency at different cantilever lengths

\begin{tabular}{ccccccccc}
\hline Length (mm) & 50 & 70 & 90 & 110 & 155 & 200 & 250 & 290 \\
\hline Exp. (Hz) & 3704 & 2369 & 1637 & 1220 & 3704 & 2369 & 1637 & 1306 \\
Analysis (Hz) & 3731 & 2367 & 1556 & 1247 & 3704 & 2376 & 1572 & 1248 \\
Error (\%) & 0.73 & -0.08 & -4.95 & 2.21 & 0.70 & 0.30 & -3.97 & -4.44 \\
\hline
\end{tabular}


According the analysis of the influence of incline angle $\alpha$ on the instability of a frictional system, for such a beam-on-disc system developed in Sect. 2, when the cantilever length is too short $(<50 \mathrm{~mm})$, the end surface of the beam almost completely contacts with the disc surface because of its high stiffness and small deflection, and the contact centre is almost the geometric centre of the end surface of the beam. The actual incline angle to the normal line of the disc is very small, and thus the frictional system is stable. When the cantilever length is too long $(>290 \mathrm{~mm})$, because the beam neutral axis deflects a lot as well as the leading area does, the actual incline angle is also very small or even negative so that the frictional system is also stable. If the cantilever length is in the range from 110 to $155 \mathrm{~mm}$, the higher order mode frequencies of the beam and disc are difficult to excite to couple with each other. These may be the reasons why there is no squeal noise generated when the cantilever length of the beam is located in some range.

\subsection{Transient Response Analysis}

In order to predict the tendency of disc brake squeal, Guan proposed a finite element analysis method of feed-in energy on the brake system [41]. The main idea is to calculate the total feed-in energy of all node pairs of a finite element model that is induced during one cycle of vibration. It was concluded that the lager the feed-in energy induced by frictional force during one cycle of vibration, the more unstable the system is, and the more frequently the squeal occurs. For the 3-DOF frictional system proposed in this paper, the kinetic energy of the system at any time can be expressed as following [42]:

$$
E_{k}(t)=\frac{1}{2} \dot{X} M \dot{X}^{T}=\frac{1}{2}\left(m_{1} \dot{x}_{1}^{2}+m_{1} \dot{y}_{1}^{2}+m_{2} \dot{y}_{2}^{2}\right)
$$

The potential energy of the system

$$
E_{p}(t)=\frac{1}{2} X K X^{T}=\frac{1}{2}\left(k_{11} x_{1}^{2}+k_{22} y_{1}^{2}+k_{33} y_{2}^{2}+2 k_{12} x_{1} y_{1}+2 k_{23} y_{1} y_{2}\right)
$$

Thus, the total energy

$$
\begin{aligned}
E_{T}(t) & =E_{k}(t)+E_{p}(t)=\frac{1}{2}\left(\dot{X} M \dot{X}^{T}+X K X^{T}\right) \\
& =\frac{1}{2}\left(m_{1} \dot{x}_{1}^{2}+m_{1} \dot{y}_{1}^{2}+m_{2} \dot{y}_{2}^{2}+k_{11} x_{1}^{2}+k_{22} y_{1}^{2}+k_{33} y_{2}^{2}+2 k_{12} x_{1} y_{1}+2 k_{23} y_{1} y_{2}\right)
\end{aligned}
$$

In order to analyse the onset of friction-induced vibration, the time response histories of the present 3-DOF model under the initial condition, $\left[x_{1}, y_{1}, y_{2}\right]_{t=0}=\left[0,0,1 \times 10^{-5}\right][\mathrm{m}]$, when the incline angle $\alpha=2^{\circ}$ and the friction coefficient $\mu=0.2$, are simulated through the transient response analysis, as shown in Fig. 9. The other parameter values for this simulation are the same as those used in Sect. 4.1. It is found that the vibration responses $x_{1}, y_{1}, y_{2}, F_{\mathrm{f}}, E_{\mathrm{k}}, E_{\mathrm{p}}$ and $E_{\mathrm{T}}$ all increase with time. In addition, the response of $y_{1}$ is more complicated than the others. The FFT analysis shows that the frequency response of $y_{1}$ consists of a large amplitude low-frequency component $(1600 \mathrm{~Hz})$ and a small amplitude high-frequency component $(10800 \mathrm{~Hz})$, as shown in Fig. 10. The latter frequency is near the vertical natural frequency of $m_{1}\left(f_{\text {tensile }}, 10907 \mathrm{~Hz}\right)$. The former frequency $(1600 \mathrm{~Hz})$ is near the horizontal natural frequency of $m_{1}\left(f_{\text {bending }}, 1563 \mathrm{~Hz}\right)$ and the vertical natural frequency of $m_{2}\left(f_{\text {out }}, 1529 \mathrm{~Hz}\right)$ and is close to the actual brake squeal frequency $(1637 \mathrm{~Hz})$. 

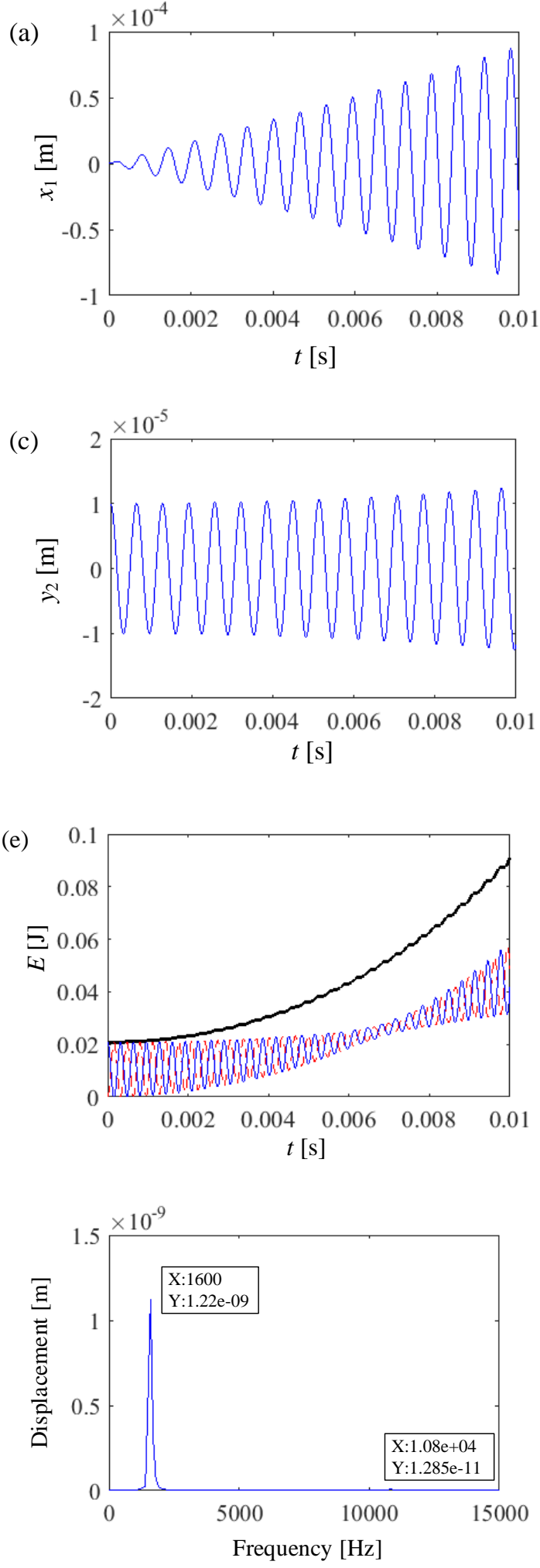
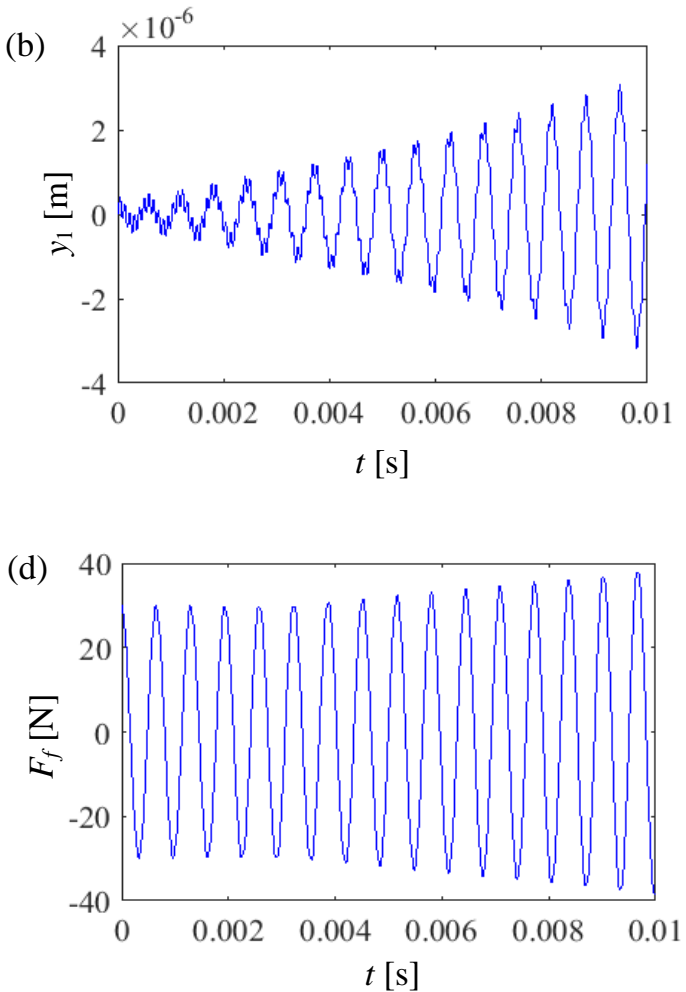

Fig. 9. Time histories of the transient response of the 3 -DOF system when the incline angle $\alpha=2^{\circ}$ and the friction coefficient $\mu=0.2$ : (a, b and c) displacement of the masses $m_{1}$ and $m_{2}$ along the $x_{1}, y_{1}$ and $y_{2}$ directions, respectively; (d) friction force between the masses $m_{1}$ and $m_{2}$ and (e) energy of the system (thin solid line represents the kinetic energy $E_{k}$ of the system; thin dashed line represents the potential energy $E_{p}$ of the system; thick solid line represents the total energy $E_{T}$ of the system).

Fig. 10. Frequency spectrum of the displacement of the mass $m_{1}$ in the $y_{1}$ direction.

It could be seen in Fig. 9 that at the beginning of the process of friction-induced vibration, $m_{1}$ moves forwards $\left(x_{1}\right)$ and downwards $\left(y_{1}\right)$ while $m_{2}$ also moves downwards $\left(y_{2}\right)$ (digging-in phase) under the action of normal force. When the frictional force $F_{\mathrm{f}}$ is gradually decreased to zero, $m_{1}$ also decreases its forward speed until it reaches zero, and then starts to move backwards and forwards followed by the motion change of $y_{2}$ (release phase), thus the frictional force $F_{\mathrm{f}}$ becomes negative. Because of the interaction of the frictional force, the 
horizontal and vertical movements of $m_{1}$ and the vertical movement of $m_{2}$, both the kinetic and potential energy, $E_{\mathrm{k}}$ and $E_{\mathrm{p}}$, of the system increase with time due to the continuous feedin energy $E_{\mathrm{T}}$ from the non-conservative frictional force, which not only keeps the digging-in and release motions of $m_{1}$ in process but also leads to increasing vibration levels of $m_{1}$ and $m_{2}$ with time and then produces a squeal noise at a coupled system frequency. Figure 9 also shows that the friction-induced vibration simulated in this paper is different from the sprag-slip behaviour [7].

When the incline angle $\alpha$ is taken as $20^{\circ}$ while friction coefficient $\mu$ is still equal to 0.2 , the time response histories are simulated and shown in Fig. 11. At the beginning of the process, the motions ( $x_{1}$ and $y_{1}$ ) of $m_{1}$ are very similar to those in Fig. 9, and the vibration amplitudes increase with time. However, the vibration amplitude of $y_{2}$ decreases with time because of the effect of phase lagging, which leads to the decreasing of normal force and frictional force. The total energy $E_{\mathrm{T}}$ of this system is therefore decreased. In the whole process, there appears a phenomenon of beating for all the variables $x_{1}, y_{1}, y_{2}$ and $F_{\mathrm{f}}$ of this 3 DOF system. Because the beat frequency is much smaller than the vibration frequency, the beating vibration might consist of two components having similar frequencies near $1600 \mathrm{~Hz}$. The beating vibrations of $x_{1}$ and $y_{1}$ are in opposite phase to those of $y_{2}$ and $F_{\mathrm{f}}$. In every cycle of beating vibration, the total feed-in energy $E_{\mathrm{T}}$ from the frictional force to the system is equal to the output energy from the system. No divergent vibration leading to squeal noise is generated because there only exists a small amount of kinetic and potential energy, $E_{\mathrm{k}}$ and $E_{\mathrm{p}}$, in the system. It is worth to note that Hoffmann also found the phenomenon of the beating oscillation occurred in a 2-DOF frictional system with closely neighbouring natural frequencies. He thought that both parameters of friction coefficient and contact stiffness have a significant influence on the energy budget of beating states [16, 43].

(a)

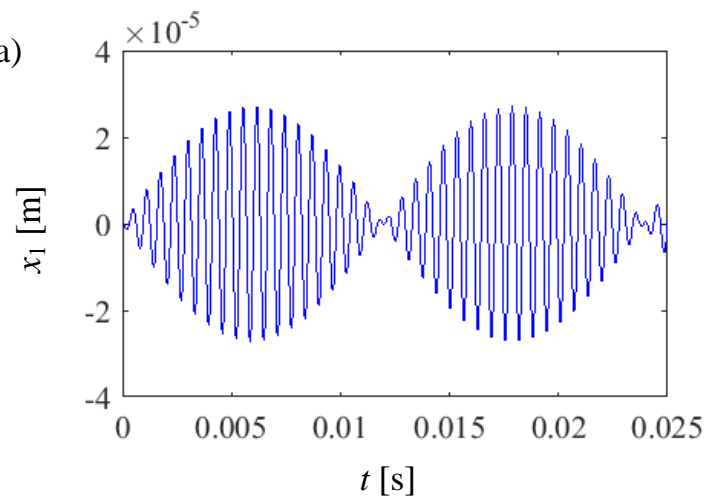

(c)

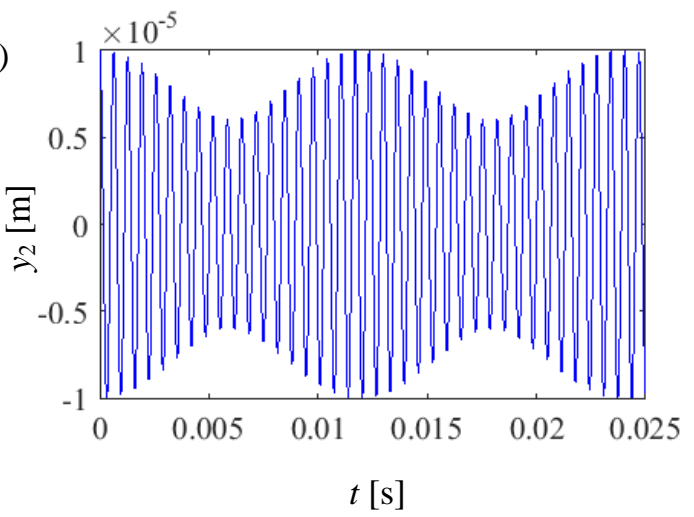

(b)

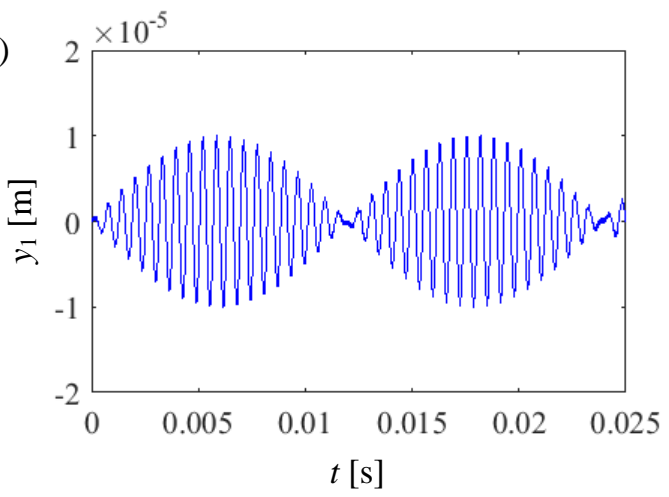

(d)

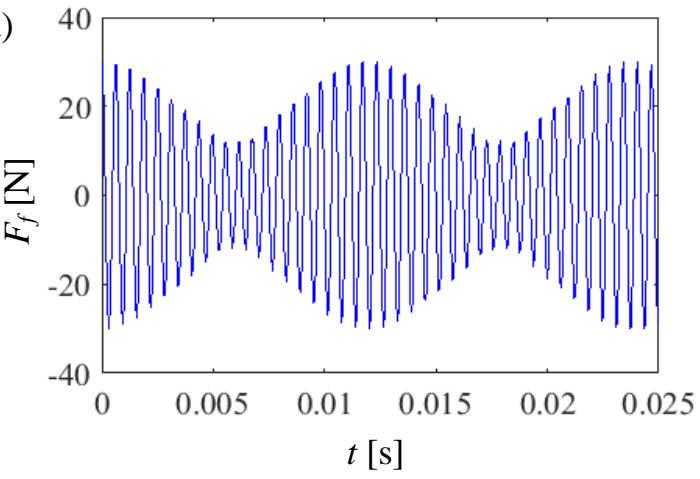


(e)

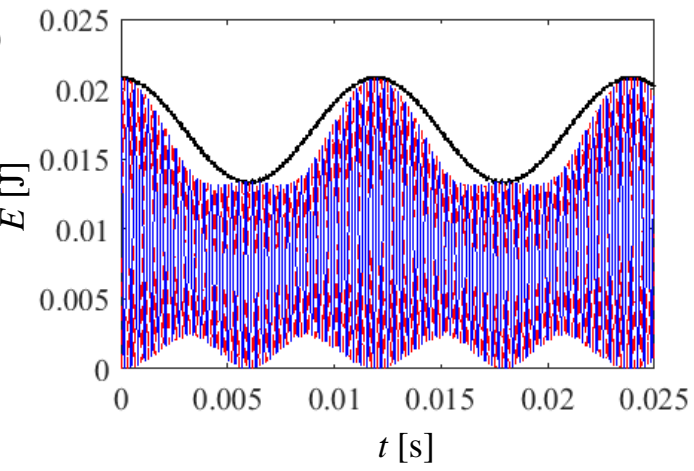

Fig. 11. Time histories of the transient response of the 3-DOF system when the incline angle $\alpha=20^{\circ}$ and the friction coefficient $\mu=0.2$ : ( $\mathrm{a}, \mathrm{b}$ and $\mathrm{c}$ ) displacement of the masses $m_{1}$ and $m_{2}$ along the $x_{1}, y_{1}$ and $y_{2}$ directions, respectively; (d) friction force between the masses $m_{1}$ and $m_{2}$ and (e) energy of the system (thin solid line represents the kinetic energy $E_{k}$ of the system; thin dashed line represents the potential energy $E_{p}$ of the system; thick solid line represents the total energy $E_{T}$ of the system).

\subsection{Influence of the Natural Frequencies on the System Instability}

Take the values of the stiffness coefficients $k_{1}$ and $k_{3}$ in a specific range with other parameters unaltered, and then convert the $k_{1}$ and $k_{3}$ into the corresponding natural frequencies $f_{1}$ and $f_{3}$ according to the following equations.

$$
f_{1}=\frac{1}{2 \pi} \sqrt{\frac{k_{1}}{m_{1}}} \text { and } f_{3}=\frac{1}{2 \pi} \sqrt{\frac{k_{3}}{m_{2}}}
$$

For different values of $f_{1}$ and $f_{3}$, the instability of the frictional system Eq. (1) can be analysed by calculating the real part $\sigma$ of the complex eigenvalue or the dimensionless damping factor $\zeta$. The relationship between the natural frequencies $\left(f_{1}\right.$ and $\left.f_{3}\right)$ and the system instability is shown in Fig. 12.

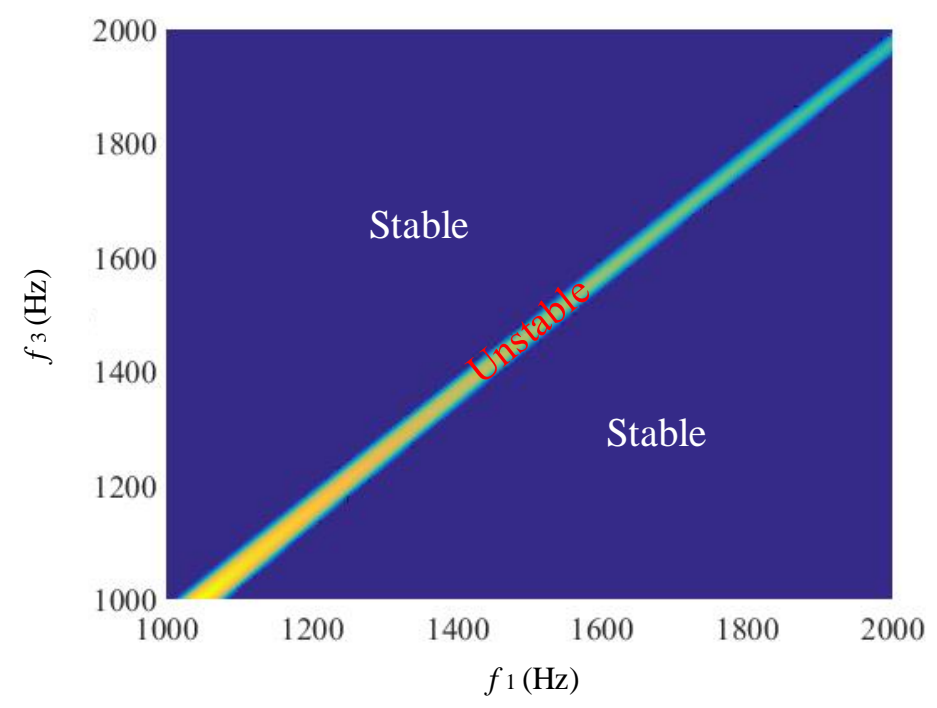

Fig. 12. Stability region of the system instability with respect to the natural frequencies $f_{1}$ and $f_{3}$.

Only when the nature frequencies $f_{1}$ and $f_{3}$ are located in the middle belt region, does the real part of the system complex eigenvalue become greater than zero, thus the frictional system is in an unstable state. But when the frequency $f_{1}$ or $f_{3}$ is increased to a certain value, i.e., they are located in the upper left or the lower right corner, the real part of the complex eigenvalue is equal to zero, and thus the system is in a stable condition. Because the contact stiffness $k_{\mathrm{c}}$ has an effect on increasing the value of the stiffness $k_{3}$ more than that of $k_{1}$, it is 
found that when the bending mode frequency $f_{1}$ of the beam is a little greater than the nodal diameter out-of-plane mode frequency $f_{3}$ of the disc, both modes of the beam and the disc are coupled to generate friction-induced vibration leading to brake squeal at a coupled frequency. When both mode frequencies are separated to a certain extent, the frictional system will transfer from the unstable state to a stable state, and the brake squeal at this coupled system frequency will disappear. The analysis agrees well with the experimental result as given in Sect. 2. According to the numerical simulation in Sects. 4.1 and 4.2, the mode coupling of the system is also influenced by the incline angle of the beam and the coefficient of friction.

\section{Conclusions}

For the simple beam-on-disc frictional apparatus developed in this paper, when the cantilever length is adjusted in a specific range, it is prone to produce squeal noise at corresponding frequencies. The frequency of squeal is near the frequencies of the first twoorder bending modes of the beam and the first four-order nodal diameter out-of-plane modes of the disc. It will not produce squeal if the cantilever length is too short or too long. When the cantilever length is too short, the end surface of the beam almost completely contacts with the disc because of its high stiffness and small deflection, and the contact centre is near the geometric centre of the beam. The actual incline angle is very small, and thus the frictional system is stable. When the cantilever length is too long, because the beam axis deflects a lot as well as the leading area does, the actual incline angle is also very small or even negative so that the frictional system is also stable. Experimental results also show that the lower order modes of the beam and disc may be easier to excite than the higher order modes to produce squeal noise, which is instructive for the reduction design of disc brake squeal.

Considering the bending and tensile modes of the beam and the nodal diameter out-ofplane mode of the disc, the incline angle of the leading area to the normal line of the disc, and the contact stiffness between the beam and the disc, a 3-DOF lumped-parameter model is proposed to investigate the generation mechanism of friction-induced vibration that occurs between two bodies. Compared to other lumped-parameter models, the proposed 3-DOF model has a definite physical meaning and can be in application to the investigation of friction-induced vibration that occurs in frictional pairs as well as the parameters can be easily identified or estimated.

Numerical simulation shows that because of the effect of the contact stiffness on the beam different from that of the disc, only when the bending mode frequency of the beam is a little greater than the frequency of the nodal diameter out-of-plane of the disc, both modes will couple with each other and lead to friction-induced vibration. It is also found that when the frictional system is transited from a steady state to an unstable state for the variation of the incline angle, its kinetic and potential energy increase with time due to continuous feedin energy from the friction force while the dynamic responses of the system change from the beating oscillation to the divergent, which results in the friction-induced vibration and squeal noise. When the incline angle is too big or too small, because of the phase changing of each degree-of-freedom, the total feed-in energy from the frictional force to the system is equal to the output energy from the system in every cycle of beating vibration. Because there only exists a small amount of kinetic and potential energy in the system, no divergent vibration is generated. 
Therefore, the bending mode frequency of the beam a little greater than the frequency of the nodal diameter out-of-plane mode and a specific incline angle of the leading area to the normal line of the disc as well as a certain friction coefficient are necessary conditions for the mode coupling of a frictional system.

\section{Acknowledgements}

This work was supported by the Production and Research Prospective Joint Research Project of Jiangsu Province (Grant No. BY2016065-40); the Six Talent Peaks Project in Jiangsu Province (Grant No. 2014-ZBZZ-025); the Natural Science Foundation of the Higher Education Institutions of Jiangsu Province (Grant No. 15KJB460017); the Jiangsu Planned Project for Postdoctoral Research Funds (Grant No. 1601062C) and Jiangsu Provincial Government Scholarship for Overseas Studies.

\section{References}

1. Akay, A.: Acoustics of friction. J. Acoust. Soc. Am. 111(4), 1525-1548 (2002)

2. Kinkaid, N.M., O'Reilly, O.M., Papadopoulos, P.: Automotive disc brake squeal. J. Sound Vib. 267(1), $105-166$ (2003)

3. Chen, F.: Automotive disk brake squeal: an overview. Int. J. Veh. Des. 51(1/2), 39-72 (2009)

4. Bowden, F.P., Leben, L.: The nature of sliding and the analysis of friction. Proc. R. Soc. Lond. A 169(938), 371-379 (1939)

5. Papinniemi, A., Lai, J.C.S., Zhao, J., Loader, L.: Brake squeal: a literature review. Appl. Acoust. 63(4), 391-400 (2002)

6. Zuleeg, J.: How to measure, prevent, and eliminate stick-slip and noise generation with lubricants. SAE Technical Paper 2015-01-2259 (2015). doi:10.4271/2015-01-2259

7. Spurr, R.: A theory of brake squeal. Proc. Automob. Div. Inst. Mech. Eng. 1, 33-40 (1961)

8. Qiao, S.L., Ibrahim, R.A.: Stochastic dynamics of systems with friction-induced vibration. J. Sound Vib. 223(1), 115-140 (1999)

9. Koenigsberger, F., Tlusty, J.: Machine Tool Structures, vol. 1. Pergamon Press, Oxford (1970)

10. North, M.R.: Frictionally induced, self excited vibrations in a disc brake system. Ph.D. Thesis, Loughborough University (1972)

11. North, M.R.: Disc brake squeal, a theoretical model. Motor Industry Research. Association (MIRA) Research Report 1972/5 (1972)

12. North, M.R.: Disc brake squeal. In: IMechE Conference on Braking of Road Vehicles. Paper C38/76, pp. 169-176 (1976)

13. Earles, S.W.E., Soar, G.B.: Squeal noise in disc brakes. In: IMechE Symposium on Vibration and Noise in Motor Vehicles, Paper C101/71, pp. 61-69 (1971)

14. Earles, S.W.E., Lee, C.K.: Instabilities arising from the frictional interaction of a pin-disc system resulting in noise generation. ASME J. Eng. Ind. 98(1), 81-86 (1976)

15. Hamabe, T., Yamazaki, I., Yamada, K., Matsui, H.: Study of a method for reducing drum brake squeal. SAE Technical Paper 1999-01-0144 (1999). doi:10.4271/1999-01-0144

16. Hoffmann, N., Fischer, M., Allgaier, R., Gaul, L.: A minimal model for studying properties of the mode-coupling type instability in friction induced oscillations. Mech. Res. Commun. 29(4), 197-205 (2002)

17. Schroth, R., Hoffmann, N., Swift, R.: Mechanism of brake squeal from theory to experimentally measured mode coupling. In: Proceedings of the 22nd International Modal Analysis Conference (IMAC XXII) (2004)

18. Millner, N.: An analysis of disc brake squeal. SAE Technical Paper 780332 (1978). doi: $10.4271 / 780332$

19. Ahmed, I.: Analysis of ventilated disc brake squeal using a 10 DOF model. SAE Technical Paper 2012-01-1827 (2012). doi:10.4271/2012-01-1827 
20. Papinniemi, A.: Vibro-acoustic studies of brake squeal noise. Ph.D. Thesis, The University of New South Wales, Australian Defence Force Academy (2007)

21. Oura, Y., Kurita, Y., Matsumura, Y., Tamura, T.: Surface contact analysis model for squeal on disk brake. Trans. Jpn. Soc. Mech. Eng. C 73(731), 1977-1984 (2007). (in Japanese)

22. Oura, Y., Kurita, Y., Matsumura, Y., Nishizawa, Y.: Influence of distributed stiffness in contact surface on disk brake squeal. SAE Technical Paper 2008-01-2584 (2008). doi:10.4271/2008-01-2584

23. Ouyang, H., Nack, W., Yuan, Y., Chen, F.: Numerical analysis of automotive disc brake squeal: a review. Int. J. Veh. Noise Vib. 1, 207-231 (2005)

24. Tuchinda, A., Hoffmann, N.P., Ewins, D.J., Keiper, W.: Mode lock-in characteristics and instability study of the pin-on-disc system. In: Proceedings of the 19th International Modal Analysis Conference (IMAC XIX), pp. 71-77 (2001)

25. Tuchinda A., Hoffman N. P., Ewins D. J.: Effect of pin finite width on instability of pin-on disc systems. In: Proceedings of the 20th International Modal Analysis Conference (IMAC XX), pp. 552-557 (2002)

26. Allgaier, R., Gaul, L., Keiper, W., Willner, K., Hoffman, N.: A study on brake squeal using a beamon-disc. In: Proceedings of the 20th International Modal Analysis Conference (IMAC XX), pp. 528-534 (2002)

27. Massi, F., Giannini, O.: Extension of a modal instability theory to real brake systems. In: Proceedings of the 23rd International Modal Analysis Conference (IMAC XXIII) (2005)

28. Oliviera, G., Akay, A., Massi, F.: Experimental analysis of brake squeal noise on a laboratory brake setup. J. Sound Vib. 292, 1-20 (2006)

29. Giannini, O., Massi, F.: Characterization of the high frequency squeal on a laboratory brake set-up. J. Sound Vib. 310, 394-408 (2008)

30. Massi, F., Giannini, O.: Effect of damping on the propensity of squeal instability: an experimental investigation. J. Acoust. Soc. Am. 123(4), 2017-2023 (2008)

31. Akay, A., Giannini, O., Massi, F., Sestieri, A.: Disc brake squeal characterization through simplified test rigs. Mech. Syst. Signal Process. 23(8), 2590-2607 (2009)

32. AbuBakar, A.R., Ouyang, H.: Complex eigenvalue analysis and dynamic transient analysis in predicting disc brake squeal. Int. J. Veh. Noise Vib. 2(2), 143-155 (2006)

33. Ouyang, H., Cao, Q., Mottershead, J.E., Treyde, T.: Vibration and squeal of a disc brake: modelling and experimental results. Proc. Inst. Mech. Eng. Part D J. Automob. Eng. 217(10), 867-875 (2003)

34. Cao, Q., Ouyang, H., Friswell, M.I., Mottershead, J.E.: Linear eigenvalue analysis of the disc-brake squeal problem. Int. J. Numer. Methods Eng. 61(9), 1546-1563 (2004)

35. Will, J.: CAE-based robustness evaluation of brake systems. SAE Technical Paper 2015-01-2656 (2015). doi:10.4271/2015-01-2656

36. Zhang, Z., Oberst, S., Lai, J.C.S.: On the potential of uncertainty analysis for prediction of brake squeal propensity. J. Sound Vib. 377(1), 123-132 (2016)

37. Fritz, G., Sinou, J.-J., Duffal, J.-M., Jézéquel, L.: Effects of damping on brake squeal coalescence patterns-application on a finite element model. Mech. Res. Commun. 34(2), 181-190 (2007)

38. Hoffmann, N., Gaul, L.: Effects of damping on mode-coupling instability in friction induced oscillations. Z. Angew. Math. Mech. 83(8), 524-534 (2003)

39. Pennacchi, P., Vania, A.: Analysis of the instability phenomena caused by steam in high pressure turbines. Shock Vib. 18(4), 593-612 (2011)

40. Pharr, G.M., Oliver, W.C., Brotzen, F.R.: On the generality of the relationship among contact stiffness, contact area, and elastic modulus during indentation. J. Mater. Res. 7(3), 613-617 (1992)

41. Guan, D., Huang, J.: The method of feed-in energy on disc brake squeal. J. Sound Vib. 261(2), 297307 (2003)

42. Zhang, L., Wu, J., Meng, D.: Relationship between two friction-induced squeal mechanisms of mode coupling and energy feed-in theories. J. Tongji Univ. (Nat. Sci.) 43(10), 1562-1569 (2015). (in Chinese) 43. Hoffmann, N., Gaul, L.: Non-conservative beating in sliding friction affected systems: transient amplification of vibrational energy and a technique to determine optimal initial conditions. Mech. Syst. Signal Process. 18(3), 611-623 (2004) 